Global Knowledge, Memory and Communication

\title{
Peer-Reviewed Physical Education Journals from Arabic- Speaking Countries: A Regional Assessment
}

\begin{tabular}{|r|l|}
\hline Journal: & Global Knowledge, Memory and Communication \\
\hline Manuscript ID & LR-09-2017-0081.R1 \\
\hline Manuscript Type: & Article \\
\hline Keywords: & $\begin{array}{l}\text { Physical education, Physical inactivity, Arabic-speaking region, Professional } \\
\text { journals, Access to research, Research publication }\end{array}$ \\
\hline \multicolumn{2}{|l}{} \\
\hline
\end{tabular}

\section{SCHOLARONE ${ }^{m}$ \\ Manuscripts}




\section{Introduction}

The Arabic-speaking region, characterized by the 22 member countries of the League of Arab States (Blair et al., 2014), is undergoing a historic transitional period across political, economic, and health systems (Jabbour, 2013; Jabbour et al., 2012) that affects individual and community health and wellness. Lack of proactive political commitment, deficiency in government-sponsored programming, limited resources, a central focus on disease treatment over disease prevention or health promotion, and the inconsistency of health and wellness policies between Arabic-speaking countries has contributed to a culture of complacency (Abdul Rahim et al., 2014; Musaiger et al., 2011). Under these conditions, prevention behaviors at the individual level, sponsored actions at the community level, and policies at the regional or national level can weaken or decline. Physical education (PE) and physical activity represent a foundational cornerstone for prevention behaviors (Titze and Oja, 2013). However, PE is adversely affected by a variety of factors such as culture, availability of sponsored or structured programs, built environments such as parks, exercise facilities, and outdoor exercise opportunities, and regional or national policy (Dagkas and Stathi, 2007). Lack of regionally-specific and culturally congruent PE research underscores these issues and might explain the decline or lack of progress in regionally-specific physical education promotion.

Non-communicable diseases (NCD) such as heart disease, diabetes, and being overweight or dealing with obesity represent the leading cause of death globally and are associated with more premature deaths each year than all other causes combined (World Health Organization, 2017). Worldwide, over $30 \%$ of adults ( $\geq 15$ years old) are considered physically inactive, with ranges from $17 \%$ in Southeast Asia to $43 \%$ in the Eastern Mediterranean region and the Americas (Hallal et al., 2012). In the Arabic-speaking region, NCD is associated with more than 
2.3 million deaths annually with increases expected in the next 10 years (World Health Organization, 2014). While the epidemiologic profile in the Arabic-speaking region includes significant variation, $\mathrm{NCD}$ have emerged as the primary cause of mortality and account for more than $50 \%$ of deaths before age 70 (International Diabetes Foundation, 2015). Globally, lack of PE has led to an estimated $30 \%$ of heart disease, $27 \%$ of diabetes, up to $25 \%$ of some cancers such as breast and colon, and approximately 1 in 5 deaths due to NCD (World Health Organization Eastern Mediterranean Regional Office, 2017). Recently, the $66^{\text {th }}$ World Health Assembly ratified an action plan for the prevention and control of NCD. Among global and regionally specific target goals, a 10\% reduction in inadequate physical activity prevalence across the lifespan was proposed and accepted (World Health Organization, 2013).

Similar national responses to recognized decreases in PE at the population level show common themes. Finland incorporated action recommendations that were developed and reported following evidence-based evaluations and regional research (Pratt et al., 2015). Brazil established monitoring efforts to assess PE in real time using national program evaluations, systems evaluations, and local partnerships between non-government organizations including universities and the private research sector (Pratt et al., 2015). The United States developed a national plan that included PE as a primary objective using ongoing and contemporary researchbased guidelines (Pratt et al., 2015). These efforts share research, publication, and dissemination as foundational elements to address decline in PE prevalence (World Health Organization Eastern Mediterranean Regional Office, 2014b). In the last 10 years, the Arabic-speaking region has experienced a significant shift away from culturally traditional dietary patterns and health behaviors and towards a westernized model that could affect social, dietary, and physical wellbeing (Aboul-Enein et al., 2016). 
Within a socio-ecological model for physical activity (World Health Organization Eastern Mediterranean Regional Office, 2014a), public health policy and infrastructure precedes all factors that influence lifestyle-related physical activity such as community assets, organizational interest and support, interpersonal relationships, and individual behavior. Current and regionally specific research and reporting provides a way to test current policies and infrastructure, and suggest new directions. Systematic analyses of PE prevalence among Arabicspeaking countries are scarce (Kahan, 2015) and there are no current evaluations of peerreviewed publications addressing PE within the Arabic-speaking region. Previous studies have assessed the status of medical, biomedical, public health, health education, and nutrition journals in the Arabic-speaking region (Aboul-Enein et al., 2017a; Aboul-Enein et al., 2017b; Tadmouri, 2004; Habibzadeh, 2006; Aly, 2004) as well as in non-Arabic speaking countries (Molina et al., 2016; Yu et al., 2013; Miranda and Mongeau, 1991; Aminpour and Kabiri, 2009; O’Connor et al., 2001; Siegfried et al., 2006). Assessment of local and regional PE journals of the Arabicspeaking region are not represented in the literature. Therefore, we investigated the availability of local and regionally active peer-reviewed PE journals in the Arab-speaking region to highlight the disparity in PE research within this region. The purpose of this assessment is to describe the difference between the need for PE journals and publications and current availability in the Arabic-speaking countries by examining the current state of PE research.

\section{Methods}

For this assessment, the authors followed the definitions, search parameters, and terms outlined in previous studies (Blair et al., 2014; Aboul-Enein et al., 2017b; Aboul-Enein et al., 2017a) as it relates to public health research in the Arabic-speaking region. An electronic search 
was conducted using 1) PubMed NLM Catalog Journals referenced in the NCBI Database records, 1) Scopus, 2) Google Scholar, 3) Science Direct, and 4) the Index Medicus for the Eastern Mediterranean Regional Office Database Journals Directory (IMEMR) and 5) the Iraqi Academic Scientific Journals database to identify relevant journals published in Arabic-speaking countries. An integrative search was carried out using a combination of search terms "Physical Education; Activity; Sports; Exercise; Training; Athletic, Kinesiology; Fitness; Human Movement; Recreation; journal AND Algeria; Bahrain; Comoros; Djibouti; Egypt; Iraq; Jordan; Kuwait; Lebanon; Libya; Mauritania; Morocco; Oman; Qatar; Saudi Arabia; Somalia; Sudan; Syria; Tunisia; United Arab Emirates; Yemen; Palestinian Territories" to identify each respective journal listed. Search results identified the corresponding journal's website which were reviewed to identify country of origin, activity status, publication period, available formats, and impact factor. Results of the electronic survey were compiled and tabulated (Table 1). For the purpose of this search, PE-affiliated journals were defined as a peer-reviewed journal with a primary focus on PE, training, exercise, sports sciences, recreation sciences, or closely-related disciplines of PE. Given the nature of this study, ethical approval and clearance was not necessary and, therefore, not obtained.

\section{Inclusion/Exclusion Criteria}

Journals that explicitly stated PE, physical training, sports sciences, recreation sciences, or closely-related disciplines of PE within the journal's respective aim and scope were included in this survey. Also, only journals that were peer-reviewed were included in this survey. Journals with a stated primary aim and scope focusing on nutrition, public health, health sciences, health education, health promotion, human medicine, veterinary medicine, nursing, and other 
discipline-specific health professions were excluded. Given the predominant languages used in this region-Arabic, English, and French-we used search terms for each. The authors acknowledge that valuable and applicable data may have been excluded as a result of this delimitation.

\section{Results}

Our electronic search generated 14 PE-affiliated journals in Arabic-speaking countries. A total of six journals preserved an active publication status into 2017 while eight journals were either interrupted or terminated (Table 1). Among the six active publications, a total of four have a publication history of 12 years or longer, two have a 4-year history, and one has been active for 2 years. Among all journals identified in this search, Iraq was represented 12 times and Saudi Arabia and Egypt were represented only once. Seven journals were accessible in both English and Arabic (Saudi Journal of Sports Medicine, Scientific Journal of Physical Education, Misan Journal for Physical Education Sciences, Karbala Journal of Physical Education Sciences, Modern Sport Journal, Al-Rafidain Journal for Sport Sciences, and Journal of studies and research of sport education), six were accessible in Arabic only (Sciences Journal of Physical Education, University of Anbar Sport and Physical Education Sciences, Journal of Physical Education, Al Qadisiya Journal for the Sciences of Physical Education, Journal of Sport Sciences, and Sport Culture), and one was accessible in English only (The International Scientific Journal of Physical Education and Sport Science). All journals in the sample offer open access for review, 13 offer electronic format only, and one offers both print and electronic format (The International Scientific Journal of Physical Education and Sport Science). With respect to the impact factor (IF), all 14 journals were unrated during 2015 and 2016. 


\section{Discussion}

Among the entire sample, no publication, current or interrupted/ceased, predates 2005 within the Arabic-speaking region. Four of the six active journals within the sample have a continuous publication history from 2005 and two are new within the last five years. Examining these findings in contrast, the United States has produced PE journals as early as 1931 (The Journal of Health and Physical Education) and Europe as early as the 1950s (professional publications in Germany, Sweden, and the United Kingdom). The link between regular physical activity as a protective factor and NCDs is established and significant. As the importance of physical activity to overall health and wellbeing grows in understanding and importance, so have the availability of PE journals within developed countries. It is unknown why this trend is conspicuously absent in the Arabic-speaking region. Given the total number of PE journals in our sample is considerably smaller than U.S and European publications, it is unknown how many (if any) PE journals existed and ceased prior to electronic archiving.

Print options and open access promotes consistent accessibility and long-term delivery of information in academic research. All 14 journals within the sample offer both electronic and open access with only one providing both print and electronic versions. Lack of reliable internet access within some Arabic-speaking countries, and comparatively low levels of e-literacy, presents a challenge within the sample. Disparities in internet access are lower in the Arabicspeaking region (56.7\%) compared to English speaking regions (88.1\%) (Internet World Stats, 2017). With reduced internet access in low income Arabic-speaking countries such as Somalia and Yemen, communicating current PE research on the regional scene and providing guidelines for PE researchers to develop and share their work in native languages may be limited or 
unavailable. Professional journals providing comprehensive access via electronic, open-access, and print versions should be reflected in Arabic-speaking region and native languages to increase information distribution, access, and understanding. From the public health perspective, this was addressed through the establishment of the Eastern Mediterranean Health Journal in 1995 (World Health Organization Eastern Mediterranean Regional Office, 2016; Aly, 2004). However, from the PE perspective, no similar journal has been established. A significant lack of print options in a region with reduced internet access and literacy presents as a significant obstacle.

Among the 14 PE-affiliated journals in Arabic-speaking countries, Iraq was represented 12 times and Saudi Arabia and Egypt were represented once. It may stand to reason that one factor influencing the number of interrupted or ceased journals in Iraq may be the growing political volatility and instability currently facing this country since the Iraq war in 2003 . These factors could be indirectly related to or influenced by post-war reconstruction activity, democratization, and a rapidly changing institutional infrastructure. While Iraq and the Arabicspeaking countries saw a minimal increase in research publication following the Iraq war, this output remained well behind Africa, Europe, and the United States (Maziak, 2011). There are multiple countries that are not represented within the Arabic-speaking region, which include Algeria; Bahrain; Comoros; Djibouti; Jordan; Kuwait; Lebanon; Libya; Mauritania; Morocco; Oman; Qatar; Somalia; Sudan; Syria; Tunisia; United Arab Emirates; Yemen; the Palestinian Territories. These include significant population centers that rely on siloed sources of information when looking for regionally produced and culturally congruent PE research.

The full sample provided languages only offered in English, Arabic, or a combination of both languages. It is noted that in other disciplines, specifically public health and nutrition 
journals published in Arabic-speaking region, French is relevant and available to accommodate a significant readership, particularly in French-speaking North Africa. Providing PE-related research publications in native languages could offer native professionals with research information and resources to address the challenges Arabic-speaking countries currently face. The International Scientific Journal of Physical Education and Sport Science, which originates in Egypt, offers a single language option: English. For health and PE practitioners to reach and serve their target populations in Arabic-speaking region, it would be important for journals to deliver written research in languages tailored to the target populations.

\section{Conclusions}

Globally, physical inactivity is one of the leading modifiable risk factors contributing to adverse health outcomes and mortality rates (Titze and Oja, 2013; Hallal et al., 2012; Kohl et al., 2012). The prevalence of physical inactivity and sedentary behaviors have been widely observed across the Arabic-speaking region (Mabry et al., 2016; Al-Hazzaa et al., 2010; Kahan, 2015; Mabry et al., 2010; Mehio Sibai et al., 2010; Hamrani et al., 2015). This contributes to the growing global public health challenge with regards to the development and endorsement of culturally congruent interventions founded on PE research produced in this region. PE journals serve as important tools and resources in the dissemination of knowledge and professional networking from evidence to practice. The disparity in the number of current PE journals as well the observed language barriers vary in the Arabic-speaking region from their American and European English counterparts. Global and regional capacity building (Ghannem, 2011) and collaborative relationships (Dean et al., 2015; Chetwood et al., 2015) are needed to advocate, 
develop, and maintain PE and physical activity research, education, and policy within this region.

For research librarians and practitioners operating in the Arabic-speaking countries, this review provides a 'snapshot' of PE journals that are culturally congruent and applicable. Stability within the research community could be realized in the form of collaborative cooperation, particularly between low-income Arab countries such as Somalia and Yemen, where native Arabic-speaking PE researchers may not have the wide-reaching access and availability of PE journals, and their middle to high income counterparts. Benefits of sustainable collaborative institutional and international partnerships between librarians, academic libraries, and research institutes can be extended between the Arab countries as well as non-Arab countries with a focus and aim in international and regional PE studies. This collaborative approach to PE research, beyond the reliance of English-based PE journals outside this region, can be coordinated between academic research institutions in high income Arab countries with their low-income counterparts. The building and sustaining of intersectoral relationships is particularly needed in Arab countries with low-to-middle incomes to help foster the case for improved regional PE research organization and could be part of an effective solution to physical inactivity at the regional level. Further development and continuity of PE journals specific to the Arabicspeaking region would help identify and promote culturally relevant policy and programmatic interventions for this region.

\section{Limitations}

There are some limitations that should be mentioned within this brief report. While the authors searched several available electronic resources and databases using various key search terms and 
phrases, some journals might have been missed. Additionally, some journals not indexed in electronic databases may have been missed in the search. It is important to note that this brief report was intended mainly to present a current status of available PE-affiliated journals in the Arabic-speaking region. 


\section{References}

Abdul Rahim, H. F., Sibai, A., Khader, Y., Hwalla, N., Fadhil, I., Alsiyabi, H., Mataria, A., Mendis, S., Mokdad, A. H. and Husseini, A. (2014), "Non-communicable diseases in the Arab world". The Lancet, Vol. 383 No. 9914, pp. 356-367, available at: http://doi.org/10.1016/S0140-6736(13)62383-1

Aboul-Enein, B. H., Bernstein, J. and Bowser, J. E. (2017a), "Peer-reviewed public health journals from Arabic-speaking countries: An updated snapshot". Journal of Public Health Policy, Vol. 38 No. 1, pp. 146-157, available at: http://doi.org/10.1057/s41271-016-00495

Aboul-Enein, B. H., Bernstein, J. and Kruk, J. (2017b), "Professional nutrition journals from Arabic-speaking countries: A regional status". Nutrition Bulletin, Vol. 42 No. 2, pp. 166171, available at: http://doi.org/10.1111/nbu.12266

Aboul-Enein, B. H., Bernstein, J. and Neary, A. (2016), "Dietary transition and obesity in selected Arabic-speaking countries: Reviewing the current evidence". Eastern Mediterranean Health Journal, Vol. 22 No. 10, pp. 753-760.

Al-Hazzaa, H. M., Musaiger, A. O. and Arab Teens Lifestyle Study Research, G. (2010), "Physical activity patterns and eating habits of adolescents living in major Arab cities. The Arab Teens Lifestyle Study". Saudi Medical Journal, Vol. 31 No. 2, pp. 210-1.

Aly, A. M. (2004), "Quality of medical journals with special reference to the Eastern Mediterranean Health Journal". Saudi Medical Journal, Vol. 25 No. 1 Suppl, pp. S18-20.

Aminpour, F. and Kabiri, P. (2009), "Science production in Iran: The scenario of Iranian medical journals". Journal of Research in Medical Sciences, Vol. 14 No. 5, pp. 313-322.

Blair, I., Grivna, M. and Sharif, A. (2014), "The "Arab World" is Not a Useful Concept When Addressing Challenges to Public Health, Public Health Education, and Research in the Middle East". Frontiers in Public Health, Vol. 2 No. 30, available at: http://doi.org/10.3389/fpubh.2014.00030

Chetwood, J. D., Ladep, N. G. and Taylor-Robinson, S. D. (2015), "Research partnerships between high and low-income countries: are international partnerships always a good thing?". BMC Medical Ethics, Vol. 16 No. 36, available at: http://doi.org/10.1186/s12910-015-0030-z

Dagkas, S. and Stathi, A. (2007), "Exploring social and environmental factors affecting adolescents' participation in physical activity". European Physical Education Review, Vol. 13 No. 3, pp. 369-384, available at: http://doi.org/doi:10.1177/1356336X07081800

Dean, L., Njelesani, J., Smith, H. and Bates, I. (2015), "Promoting sustainable research partnerships: a mixed-method evaluation of a United Kingdom-Africa capacity strengthening award scheme". Health Research Policy and Systems, Vol. 13 No. 81, available at: http://doi.org/10.1186/s12961-015-0071-2

Ghannem, H. (2011), "The need for capacity building to prevent chronic diseases in North Africa and the Middle East". Eastern Mediterranean Health Journal, Vol. 17 No. 7, pp. 630632.

Habibzadeh, F. (2006), "A snapshot of medical journals from the Middle East". The Lancet, Vol. 367 No. 9515, pp. 978, available at: http://doi.org/10.1016/S0140-6736(06)68411-0 
Hallal, P. C., Andersen, L. B., Bull, F. C., Guthold, R., Haskell, W. and Ekelund, U. (2012), "Global physical activity levels: surveillance progress, pitfalls, and prospects". Lancet, Vol. 380 No. 9838, pp. 247-257, available at: http://doi.org/10.1016/s01406736(12)60646-1

Hamrani, A., Mehdad, S., El Kari, K., El Hamdouchi, A., El Menchawy, I., Belghiti, H., El Mzibri, M., Musaiger, A. O., Al-Hazzaa, H. M., Hills, A. P., Mokhtar, N. and Aguenaou, H. (2015), "Physical activity and dietary habits among Moroccan adolescents". Public Health Nutrition, Vol. 18 No. 10, pp. 1793-1800, available at: http://doi.org/10.1017/S1368980014002274

International Diabetes Foundation. (2015), "Diabetes atlas update for 2015", Available at: http://www.diabetesatlas.org/resources/2015-atlas.html [Accessed March 21 2017].

Internet World Stats. (2017), "Usage and population statistics", Available at: http://www.internetworldstats.com/stats.htm [Accessed March 28 2017].

Jabbour, S. (2013), "Public health in the Arab World: At a crossroads". Journal of Public Health Policy, Vol. 34 No. 2, pp. 356-360, available at: http://doi.org/10.1057/jphp.2013.2

Jabbour, S., Giacaman, R., Khawaja, M. and Nuwayhid, I. (2012), "Public health in the Arab world", Cambridge, UK, Cambridge University Press.

Kahan, D. (2015), "Adult physical inactivity prevalence in the Muslim world: Analysis of 38 countries". Preventive Medicine Reports, Vol. 2 No. 71-75, available at: http://doi.org/10.1016/j.pmedr.2014.12.007

Kohl, H. W., 3rd, Craig, C. L., Lambert, E. V., Inoue, S., Alkandari, J. R., Leetongin, G. and Kahlmeier, S. (2012), "The pandemic of physical inactivity: global action for public health". Lancet, Vol. 380 No. 9838, pp. 294-305, available at: http://doi.org/10.1016/s0140-6736(12)60898-8

Mabry, R., Koohsari, M., Bull, F. and Owen, N. (2016), "A systematic review of physical activity and sedentary behaviour research in the oil-producing countries of the Arabian Peninsula". BMC Public Health, Vol. 16 No. 1, pp. 1003, available at: http://doi.org/10.1186/s12889-016-3642-4

Mabry, R. M., Reeves, M. M., Eakin, E. G. and Owen, N. (2010), "Evidence of physical activity participation among men and women in the countries of the Gulf cooperation council: a review". Obesity reviews, Vol. 11 No. 6, pp. 457-464, available at: http://doi.org/10.1111/j.1467-789X.2009.00655.x

Maziak, W. (2011). "Boosting biomedical research in the Arab world". Avicenna Journal of Medicine, Vol. 1 No. 1, pp. 2-3, available at: http://doi.org/10.4103/2231-0770.83715

Mehio Sibai, A., Nasreddine, L., Mokdad, A. H., Adra, N., Tabet, M. and Hwalla, N. (2010), "Nutrition transition and cardiovascular disease risk factors in Middle East and North Africa countries: reviewing the evidence". Annals of nutrition \& metabolism, Vol. 57 No. 3-4, pp. 193-203, available at: http://doi.org/10.1159/000321527

Miranda, M. and Mongeau, D. (1991), "An Evaluation of Journals in Physical Education, Athletics, and Sports". The Serials Librarian, Vol. 21 No. 1, pp. 89-113, available at: http://doi.org/10.1300/J123v21n01_07

Molina, P., Martínez-Baena, A. and Villamón, M. (2016), "Physical Education Pedagogy: an analysis of research published in Spanish journals (2005-2014)". Physical Education and Sport Pedagogy, Vol. 22 No. 4, pp. 378-389, available at: http://doi.org/10.1080/17408989.2016.1241225 
Musaiger, A. O., Hassan, A. S. and Obeid, O. (2011), "The paradox of nutrition-related diseases in the Arab countries: The need for action". International Journal of Environmental Research and Public Health, Vol. 8 No. 9, pp. 3637-3671, available at: http://doi.org/10.3390/ijerph8093637

O’Connor, J., French, R., Sherrill, C. and Babcock, G. (2001), "Scholarly productivity in adapted physical activity pedagogy: A bibliometric analysis". Adapted Physical Activity Quarterly, Vol. 18 No. 4, pp. 434-450, available at: http://doi.org/10.1123/apaq.18.4.434

Pratt, M., Perez, L. G., Goenka, S., Brownson, R. C., Bauman, A., Sarmiento, O. L. and Hallal, P. C. (2015), "Can population levels of physical activity be increased? Global evidence and experience". Progress in cardiovascular diseases, Vol. 57 No. 4, pp. 356-367, available at: http://doi.org/10.1016/j.pcad.2014.09.002

Siegfried, N., Busgeeth, K. and Certain, E. (2006), "Scope and geographical distribution of African medical journals active in 2005". South African Medical Journal, Vol. 96 No. 6, pp. 533-537.

Tadmouri, G. O. (2004), "Biomedical science journals in the Arab world". Saudi Medical Journal, Vol. 25 No. 10, pp. 1331-1336.

Titze, S. and Oja, P. (2013), "Global Advocacy for Physical Activity". Public Health Forum, Vol. 21 No. 2, pp. 34.e1-34.e3, available at: http://doi.org/10.1016/j.phf.2013.03.018 World Health Organization. (2013), "Global Action Plan for the Prevention and Control of NCDs 2013-2020" , Available at: http://www.who.int/nmh/events/ncd_action_plan/en/ [Accessed December 25 2016].

World Health Organization. (2014), "Global status report on noncommunicable diseases 2014", Geneva, Switzerland: World Health Organization, Available at: http://www.who.int/nmh/publications/ncd-status-report-2014/en/ [Accessed January 21 2017].

World Health Organization. (2017), "Global Health Observatory (GHO) data", Geneva, Switzerland, Available at: http://www.who.int/gho/mortality_burden_disease/en/ [Accessed May 25 2017].

World Health Organization Eastern Mediterranean Regional Office. (2014a), "Promoting physical activity in the Eastern Mediterranean Region through a life-course approach", Geneva, Switzerland: World Health Organization, Available at: http://apps.who.int/iris/handle/10665/116901 [Accessed February 8 2017].

World Health Organization Eastern Mediterranean Regional Office. (2014b), "Promoting physical activity through the life course: A regional call to action", Available at: http://applications.emro.who.int/dsaf/EMROPUB_2014_EN_1697.pdf?ua=1 [Accessed February 8 2017].

World Health Organization Eastern Mediterranean Regional Office. (2016), "Eastern Mediterranean Health Journal" , Cairo, Egypt, Available at: http://www.emro.who.int/emh-journal/eastern-mediterranean-health-journal/home.html [Accessed June 10 2016].

World Health Organization Eastern Mediterranean Regional Office. (2017), "Health education and promotion: Physical activity" , Geneva, Switzerland: World Health Organization, Available at: http://www.emro.who.int/health-education/physicalactivity/background.html [Accessed May 2 2017]. 
Yu, Q. H., Zhang, Y. W., Li , Y. Z., Bai, S. P., Xiao, F. X. and Li, Q. H. (2013), "Bibliometric analysis of advances in clinical nutrition in Chinese journals". Chinese Journal of Clinical Nutrition, Vol. 21 No. 1, pp. 35-41. 
Table 1. Physical Education-affiliated Journals in Arabic-speaking Countries

\begin{tabular}{|c|c|c|c|c|c|c|c|}
\hline Journal Name & $\begin{array}{l}\text { Publication } \\
\text { Period }^{\mathrm{a}}\end{array}$ & $\begin{array}{l}\text { Activity } \\
\text { Status }\end{array}$ & $\begin{array}{l}\text { Country } \\
\text { Origin }\end{array}$ & Language $^{b}$ & $\begin{array}{l}\text { Print } \\
\text { Format }\end{array}$ & $\begin{array}{l}\text { Open } \\
\text { Access }\end{array}$ & $\mathbf{I . F}^{\mathrm{e}}$ \\
\hline $\begin{array}{l}\text { Saudi Journal of Sports } \\
\text { Medicine }\end{array}$ & 2013-present & Current & $\begin{array}{l}\text { Saudi } \\
\text { Arabia }\end{array}$ & Eng; Ara & Electronic & Yes & $\mathrm{N} / \mathrm{A}$ \\
\hline $\begin{array}{l}\text { The International Scientific } \\
\text { Journal of Physical Education } \\
\text { \& Sport Science }\end{array}$ & 2015-present & Current & Egypt & Eng & Both & Yes & N/A \\
\hline $\begin{array}{l}\text { Sciences Journal Of Physical } \\
\text { Education }\end{array}$ & $2005-2015$ & Interrupted/ceased & Iraq & Ara & Electronic & Yes & N/A \\
\hline $\begin{array}{l}\text { University of Anbar Sport and } \\
\text { Physical Education Sciences }\end{array}$ & $2009-2013$ & Interrupted/ceased & Iraq & Ara & Electronic & Yes & N/A \\
\hline Journal of Physical Education & 2005-present & Current & Iraq & Ara & Electronic & Yes & N/A \\
\hline $\begin{array}{l}\text { Scientific Journal Of Physical } \\
\text { Education }\end{array}$ & $2012-2013$ & Interrupted/ceased & Iraq & Eng; Ara & Electronic & Yes & N/A \\
\hline $\begin{array}{l}\text { Misan Journal for Physical } \\
\text { Education Sciences }\end{array}$ & 2009-2015 & Interrupted/ceased & Iraq & Eng; Ara & Electronic & Yes & N/A \\
\hline $\begin{array}{l}\text { Al Qadisiya Journal for the } \\
\text { Sciences of Physical } \\
\text { Education }\end{array}$ & 2005-present & Current & Iraq & Ara & Electronic & Yes & N/A \\
\hline $\begin{array}{l}\text { Karbala Journal of Physical } \\
\text { Education Sciences }\end{array}$ & $2012-2015$ & Interrupted/ceased & Iraq & Eng; Ara & Electronic & Yes & N/A \\
\hline Journal of Sport Sciences & 2009-2015 & Interrupted/ceased & Iraq & Ara & Electronic & Yes & N/A \\
\hline Modern Sport Journal & 2005-current & Current & Iraq & Eng; Ara & Electronic & Yes & N/A \\
\hline $\begin{array}{l}\text { Al-Rafidain Journal For Sport } \\
\text { Sciences }\end{array}$ & $2005-2014$ & Interrupted/ceased & Iraq & Eng; Ara & Electronic & Yes & N/A \\
\hline Sport Culture & 2009-2013 & Interrupted/ceased & Iraq & Ara & Electronic & Yes & N/A \\
\hline $\begin{array}{l}\text { Journal of studies and } \\
\text { researches of sport education }\end{array}$ & 2005-present & Current & Iraq & Eng; Ara & Electronic & Yes & $\mathrm{N} / \mathrm{A}$ \\
\hline
\end{tabular}

researches of sport education

${ }^{\mathrm{a}}$ Information obtained from PubMed or IMEMR database

${ }^{\mathrm{b}}$ Eng - English; Ara - Arabic; Fre - French

c Paper; electronic; Both

${ }^{\mathrm{d}}$ N/A - Information not available

${ }^{\mathrm{e}}$ I.F - Impact Factor (2015-2016) 